\title{
HPLC Analysis of the Urinary Iodine Concentration in Pregnant Women
}

\author{
Aniceta A. Mikulska ${ }^{1,+}{ }^{\circledR}$, Dorota Filipowicz ${ }^{2,+}{ }^{,}$Franciszek K. Główka ${ }^{1}\left(\mathbb{D}\right.$, Ewelina Szczepanek-Parulska ${ }^{2}$, \\ Marek Ruchała $^{2}$ D, Michał Bartecki ${ }^{3}$ and Marta Karaźniewicz-Łada ${ }^{1, *(D)}$ \\ 1 Department of Physical Pharmacy and Pharmacokinetics, Poznan University of Medical Sciences, \\ 60-781 Poznań, Poland; amikulska@ump.edu.pl (A.A.M.); glowka@ump.edu.pl (F.K.G.) \\ 2 Department of Endocrinology, Metabolism and Internal Medicine, Poznan University of Medical Sciences, \\ 60-356 Poznań, Poland; dorota.filipowicz123@gmail.com (D.F.); ewelina@ump.edu.pl (E.S.-P.); \\ mruchala@ump.edu.pl (M.R.) \\ 3 Department of Pediatric Cardiology, Poznan University of Medical Science, 60-572 Poznań, Poland; \\ mbartecki@ump.edu.pl \\ * Correspondence: mkaraz@ump.edu.pl; Tel.: +48-(0)6-1854-6435 \\ + These authors contributed equally to this work.
}

Citation: Mikulska, A.A.;

Filipowicz, D.; Główka, F.K.;

Szczepanek-Parulska, E.; Ruchała, M.; Bartecki, M.; Karaźniewicz-Łada, M. HPLC Analysis of the Urinary Iodine Concentration in Pregnant Women. Molecules 2021, 26, 6797. https:// doi.org/10.3390/molecules26226797

Academic Editor: Roberto Mandrioli

Received: 7 October 2021

Accepted: 6 November 2021

Published: 10 November 2021

Publisher's Note: MDPI stays neutral with regard to jurisdictional claims in published maps and institutional affiliations.

Copyright: (c) 2021 by the authors. Licensee MDPI, Basel, Switzerland. This article is an open access article distributed under the terms and conditions of the Creative Commons Attribution (CC BY) license (https:// creativecommons.org/licenses/by/ $4.0 /)$.

\begin{abstract}
Iodine is an essential component for fetal neurodevelopment and maternal thyroid function. Urine iodine is the most widely used indicator of iodine status. In this study, a novel validated ion-pair HPLC-UV method was developed to measure iodine concentration in clinical samples. A sodium thiosulfate solution was added to the urine sample to convert the total free iodine to iodide. Chromatographic separation was achieved in a Pursuit XRs C8 column. The mobile phase consisted of acetonitrile and a water phase containing 18-crown-6-ether, octylamine and sodium dihydrogen phosphate. Validation parameters, such as accuracy, precision, limits of detection and quantification, linearity and stability, were determined. Urinary samples from pregnant women were used to complete the validation and confirm the method's applicability. In the studied population of 93 pregnant women, the median UIC was lower in the group without iodine supplementation (117 $\mu \mathrm{g} / \mathrm{L}$, confidence interval (\%CI): 95; 138) than in the supplement group (133 $\mu \mathrm{g} / \mathrm{L}, \% \mathrm{CI}: 109 ; 157)$. In conclusion, the newly established ion-pair HPLC-UV method was adequately precise, accurate and fulfilled validation the criteria for analyzing compounds in biological fluids. The method is less complicated and expensive than other frequently used assays and permits the identification of the iodine-deficient subjects.
\end{abstract}

Keywords: ion-pair HPLC-UV method; validation; in vivo application; iodine supplementation; pregnancy

\section{Introduction}

Iodine and selenium are crucial microelements for the proper functioning of the thyroid gland, including the synthesis of triiodothyronine (T3) and thyroxine (T4). They are closely related to fetal neurodevelopment, growth and basic metabolism [1-4]. Iodine deficiency (ID) is considered one of the major public health problems worldwide [3,5]. The primary strategy for the elimination of ID is universal salt iodization. Iodine deficiency prevention with global salt iodization programs began in the 20th century. Currently, it is recommended to limit salt intake, which is the main source of iodine, owing to the increased incidence of hypertension and other cardiovascular diseases [6-8]. Consequently, the consumption of various iodine-rich products, including seafood, fish, dairy products, eggs and meat, should be increased [9]. Nowadays, after a successful salt iodization program in Poland, the country is considered iodine-sufficient, but these analyses are not relevant to pregnant and lactating females [10]. During pregnancy, the thyroid hormones T4 and T3 production increase by almost $50 \%$, which requires a higher iodine supply. As a result, 
salt iodization and iodine intake are insufficient [11,12], and additional supplementation is recommended in pregnant women [13]. Women who take an adequate dose of iodine before and during pregnancy have enough iodine stores and have no difficulty in adapting to the increased demand for thyroid hormones; accordingly, iodine levels remain stable throughout this period. In areas with mild-to-moderate iodine deficiency, iodine stores decline gradually from the first to the third trimester of pregnancy [9].

Iodine deficiency disorders depend on the severity and duration of dietary iodine deficiency at certain stages of life, particularly during fetal and infant development $[2,14]$. ID is the world's leading cause of mental retardation in children and may impair the normal growth and development of the child, significantly affecting neurogenesis $[9,14-16]$. Severe ID during pregnancy (urinary iodine concentration (UIC) $<50 \mu \mathrm{g} / \mathrm{L}$ ) is associated with many irreversible adverse effects, including disturbed nerve myelination, central nervous system (CNS) damage and cretinism, as well as an increased risk of miscarriage and premature birth. It may also lead to hypothyroidism in pregnant women and the fetus. Mild-to-moderate iodine deficiency (UIC of 50-149 $\mu \mathrm{g} / \mathrm{L}$ ) may also be associated with impaired psychomotor development, attention deficit hyperactivity disorders (ADHD) [11], decreased Intelligence Quotient (IQ) [17-19] and impaired cognitive outcomes [18,20]. Iodine supplementation during the pre-contraceptive period and in early pregnancy may reduce the risk of these disorders [13,15].

During pregnancy, the requirement for iodine increases [13]. The daily iodine intake recommended by the World Health Organization (WHO) for pregnant women is $250 \mu \mathrm{g} /$ day. To achieve the proper daily intake of iodine, it is necessary to consume iodized table salt and additional supplementation of iodine (150-200 $\mu \mathrm{g}$ iodine) in the form of potassium iodide (KI) or multivitamin supplements containing KI [21]. The American Thyroid Association (ATA) recommends additional dietary daily iodine supplementation of $150 \mu \mathrm{g}$ in the form of KI for pregnant women, which should be started three months in advance of planned pregnancy [9].

The effectiveness of iodine prophylaxis in pregnant women should be monitored [22,23]. The most common biomarkers for analyzing iodine status are UIC, serum thyroid-stimulating hormone, thyroglobulin levels, and thyroid volume [2,13,24-26]. More than $90 \%$ of absorbed iodine is excreted through the kidneys, so the UIC is the most widely used indicator of iodine status at the population level $[26,27]$. There are three methods for reporting the iodine status value from spot urinary collection. These methods include simple UIC, iodine-to-creatinine ratio (I/Cr) and estimated age/sex-adjusted $24 \mathrm{~h}$ iodine excretion [25,28]. Measurement of a spot UIC is commonly used and recommended by the WHO as a good tool for assessing iodine status in a population [22,29].

Table 1 shows the WHO reference values of median UIC for the classification of iodine concentration in pregnant women [23]. According to the WHO guidelines, the median UIC for pregnant women between 150 and $249 \mu \mathrm{g} / \mathrm{L}$ is consistent with adequate iodine intake $[9,22,23]$.

Table 1. Median UIC categories in pregnant women according to the WHO [23].

\begin{tabular}{cc}
\hline $\begin{array}{c}\text { Category of Iodine Supply } \\
\text { in Pregnant Women }\end{array}$ & Median Urinary Iodine Concentration [ $\mu \mathrm{g} / \mathrm{L}]$ \\
\hline Insufficient & $<150$ \\
Adequate & $150-249$ \\
Above requirements & $250-499$ \\
Excessive & $\geq 500$ \\
\hline
\end{tabular}

Several analytical methods are available for measuring UIC, but only a few are routinely used. Most of them require a time-consuming sample preparation step or costly detection systems. Currently, inductively coupled plasma mass spectrometry (ICP-MS), characterized by high specificity and sensitivity, is considered the method of choice to provide a reliable measurement of UIC. However, ICP-MS equipment is not easily available 
in all laboratories, and requires qualified staff to operate it [30-34]. The other commonly used technique for iodine measurement is the time-consuming spectrophotometric method based on the Sandell-Kolthoff (S-K) reaction. In this procedure, iodide catalyzes the reduction of yellow-colored tetra-ammonium cerium (IV) sulfate to the colorless cerous form by arsenite, allowing the spectrophotometric detection of the color disappearance. The S-K method requires complex sample preparation, including digestion at high temperature and the use of significantly hazardous chemicals such as arsenic and cerium. Moreover, urine contains substances that can interfere with the compounds of the S-K reaction [31]. Most studies indicate that the above methods are comparable in terms of precision and accuracy, especially when the UIC is less than $300 \mu \mathrm{g} / \mathrm{L}$, which covers the normal adult UIC range [31,34-36]. Up to now, only one high-performance liquid chromatography with ultraviolet detection (HPLC-UV) method has been described to determine iodine in biological fluids. The method applied simple protein precipitation with acetonitrile and a mobile phase with ion-pairing reagents to analyze iodine in rabbit plasma [37]. The ion-pair HPLC-UV method is a widely used analytical method. This technique is applied to separate compounds, including iodide, that contain ionizable or strongly polar groups that lead to poor retention of these compounds on the reversed-phase column [38].

Considering the importance of iodine deficiency detection and increased demand for iodine status determination, it is clear that a simple analytical method that could be easily available is needed. Therefore, this study aimed to develop and validate a simple ion-pair HPLC-UV method to determine iodine urine concentration in clinical samples and apply the method to assess iodine supplies in pregnant women.

\section{Results}

\subsection{Development of the Ion-Pair HPLC-UV Method}

In the developed conditions, the retention time of $\mathrm{I}^{-}$was about $15.5 \mathrm{~min}$. The representative chromatograms of the blank sample, standard samples (at concentrations equal to limit of detection (LOD), limit of quantitation (LOQ) and $200 \mu \mathrm{g} / \mathrm{L}$ ), and a urine sample of the pregnant woman are displayed in Figure 1.

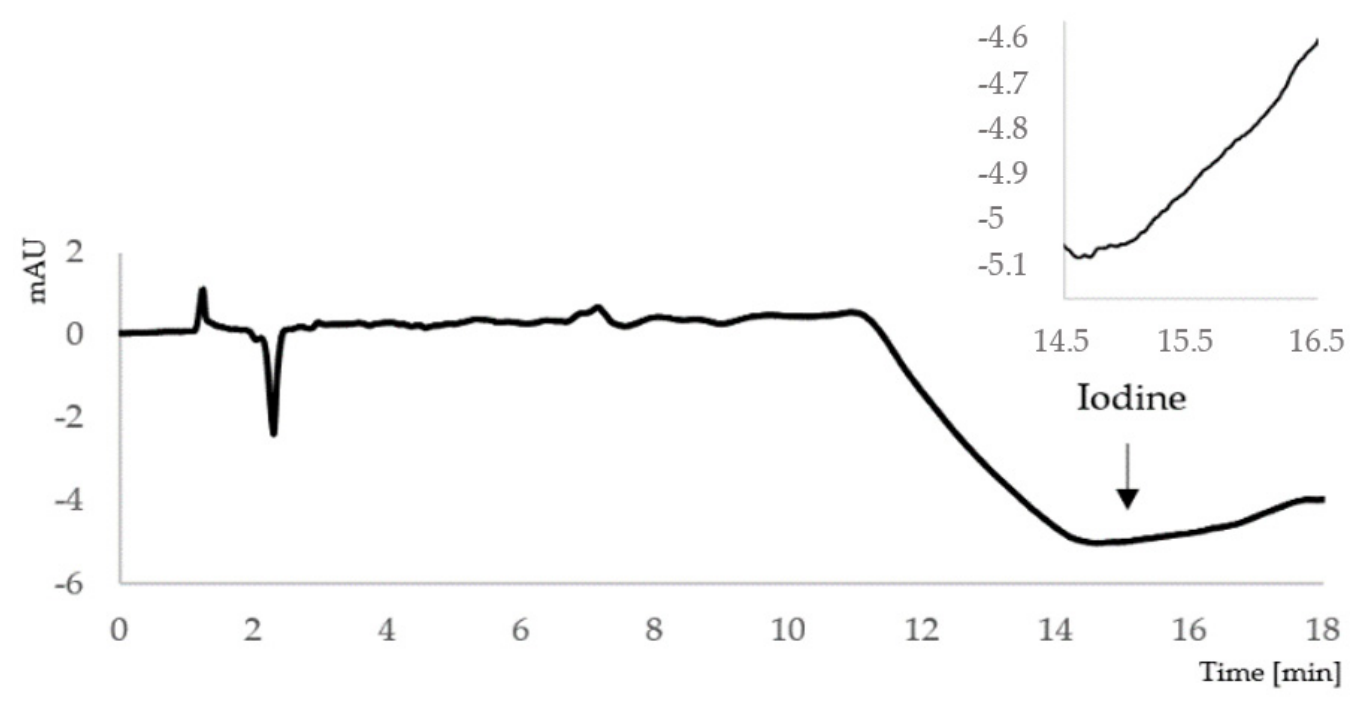

(A)

Figure 1. Cont. 


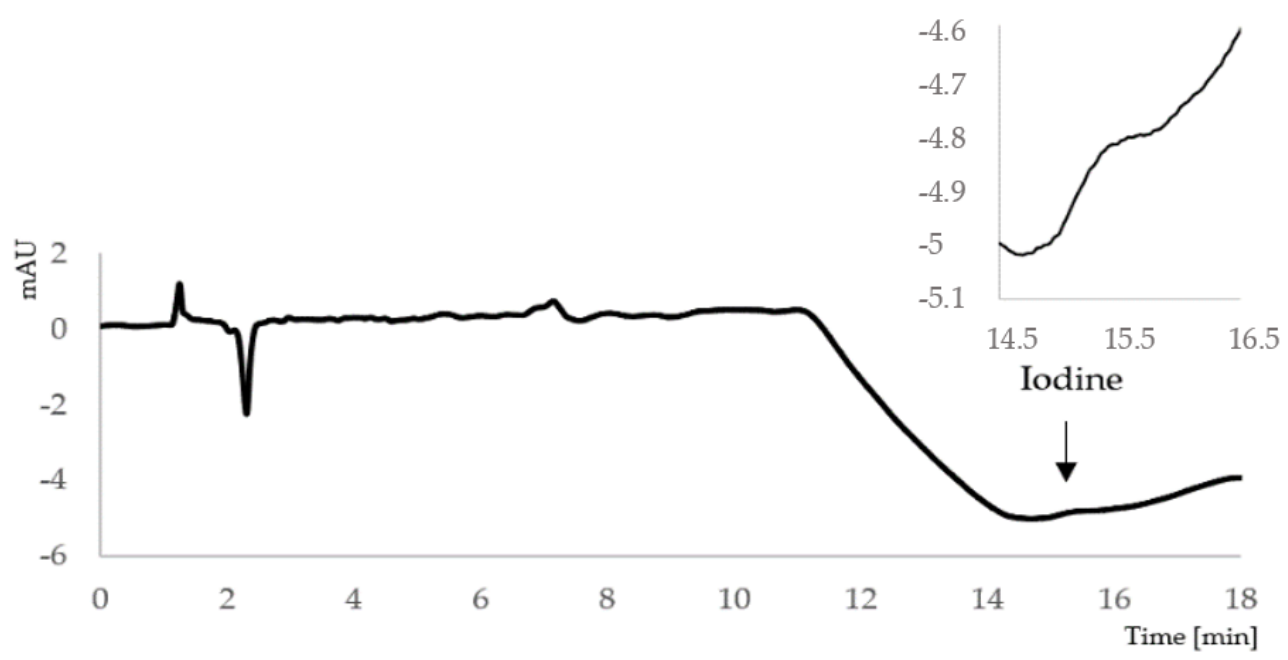

(B)

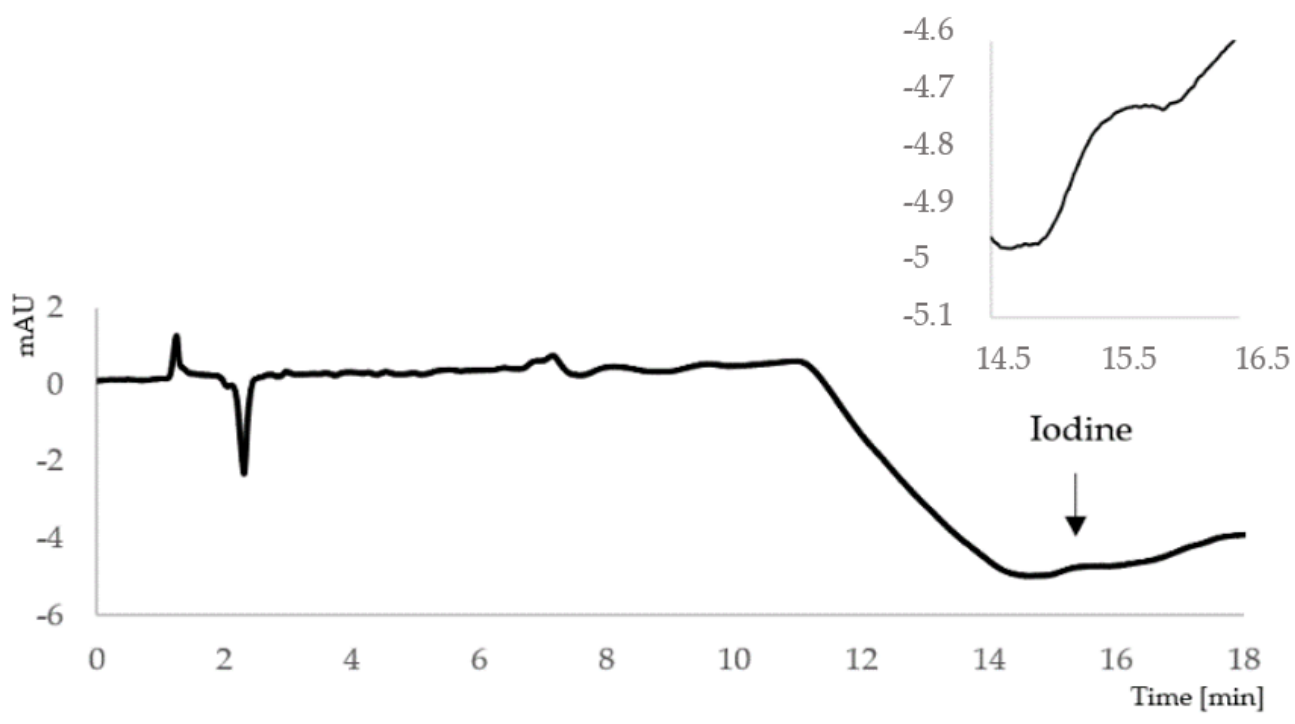

(C)

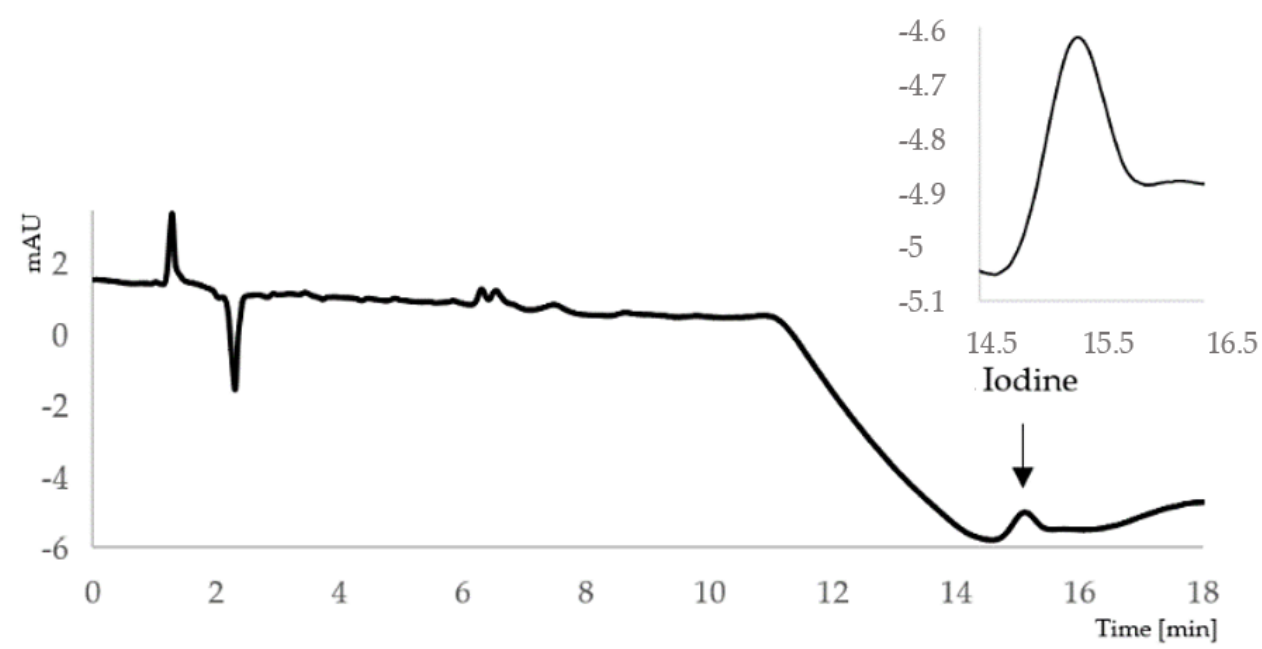

(D)

Figure 1. Cont. 


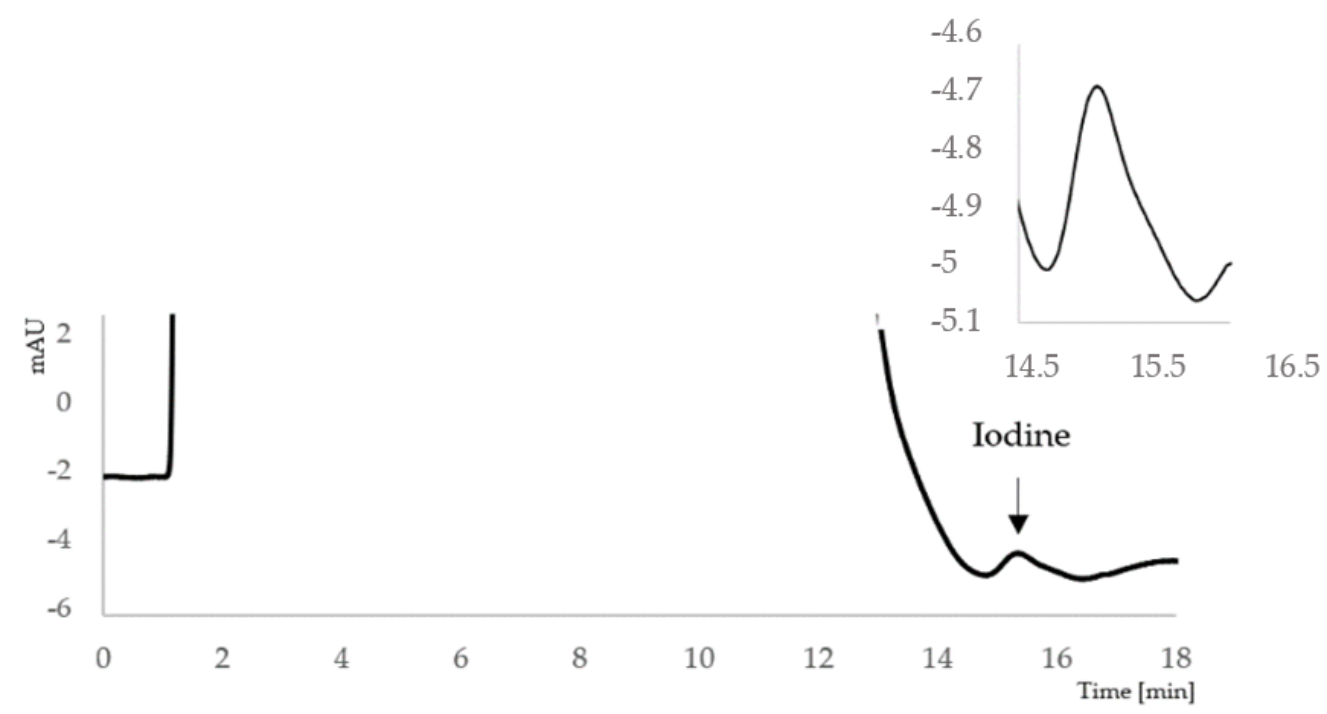

(E)

Figure 1. Representative chromatograms of (A) blank sample; (B) limit of detection (LOD); (C) limit of quantitation (LOQ); (D) calibration standard at concentration $200 \mu \mathrm{g} / \mathrm{L}$; (E) urine sample of the pregnant woman (determined iodine concentration $271 \mu \mathrm{g} / \mathrm{L}$ ). HPLC conditions: Pursuit XRs C8 column $(250 \times 4.0 \mathrm{~mm}, 5 \mu \mathrm{m})$; mobile phase: mixture of water phase (18-crown-6 ether, octylamine, sodium dihydrogen phosphate; $\mathrm{pH} 5.95)$ and acetonitrile (88:12, v/v); UV detection at $225 \mathrm{~nm}$.

\subsection{Validation Results}

\subsubsection{Linearity, LOD and LOQ}

The linearity of the method was evaluated at seven concentration levels. The resulting peak areas were processed and calibration curves were generated by Microsoft Excel. The standard calibration curves were linear over the concentration range of 50-300 $\mu \mathrm{g} / \mathrm{L}$, covering the required range for the analysis of iodine. The average equation of the calibration curve was: $y=66.6 x$. The correlation coefficient $(r)$ for standard curves was 0.9994, indicating the method linearity. To check the significance of the value of $b$, Student's $t$-test was performed. Under the stated experimental conditions, LOQ for the iodine analysis was $50 \mu \mathrm{g} / \mathrm{L}$ and LOD was $18 \mu \mathrm{g} / \mathrm{L}$, which were sensitive enough for clinical utility.

\subsubsection{Accuracy and Precision}

The validation results of the inter-day and intra-day accuracy and precision shown in Table 2 were within the European Medicines Agency (EMA) guidelines [39]. Intra-day and inter-day precision expressed by the relative standard deviation (\%RSD) were less than $10 \%$. Accuracy determined by relative error (\%RE) was below 10\%, except for the LOQ, which was $20 \%$.

Table 2. Intra-day and inter-day precision and accuracy.

\begin{tabular}{ccccc}
\hline \multirow{2}{*}{ QCs Concentration } & \multicolumn{2}{c}{ Precision (RSD, \%) } & \multicolumn{2}{c}{ Accuracy (\%RE) } \\
\cline { 2 - 5 } & Within-Run & Between-Run & Within-Run & Between-Run \\
& $\boldsymbol{n}=\mathbf{5}$ & $\boldsymbol{n}=\mathbf{5}$ & $\boldsymbol{n}=\mathbf{5}$ & $\boldsymbol{n}=\mathbf{5}$ \\
\hline LOQ $(50 \mu \mathrm{g} / \mathrm{L})$ & 1.07 & 9.72 & 20.00 & 9.43 \\
Low $(75 \mu \mathrm{g} / \mathrm{L})$ & 8.44 & 9.12 & 0.06 & 2.16 \\
Medium $(150 \mu \mathrm{g} / \mathrm{L})$ & 8.57 & 9.71 & 4.88 & 4.77 \\
High $(250 \mu \mathrm{g} / \mathrm{L})$ & 2.92 & 4.69 & 0.38 & 0.99 \\
\hline
\end{tabular}

QCs—quality control samples; LOQ—limit of quantitation, $n$-number of samples; \%RSD—relative standard deviation; \%RE-relative error. 


\subsubsection{Stability}

For the stability evaluation of iodine in urine samples, the differences were calculated between the initial concentration and the concentration found after defined storage conditions. All analyses were performed for patient samples containing iodine at a low, medium and high level. The samples were prepared according to the procedure described in Section 4.4. The deviations expressed as \%RE were within acceptable limits of $\pm 15 \%$. The results of stability assessment of iodine under various conditions, including long-term, short-term, autosampler and freeze-thaw stability, are illustrated in Table 3.

Table 3. The stability of iodine in urine samples under different conditions.

\begin{tabular}{|c|c|c|c|}
\hline Concentration & High $(n=3)$ & Medium $(n=3)$ & Low $(n=3)$ \\
\hline \multicolumn{4}{|c|}{ Long-term stability ( $-20^{\circ} \mathrm{C}$ for 2 months) } \\
\hline Initial concentration (mean $\pm \mathrm{SD}, \mu \mathrm{g} / \mathrm{L})$ & $273 \pm 2$ & $145 \pm 15$ & $68.2 \pm 6.0$ \\
\hline Concentration determined after stability study (mean $\pm \mathrm{SD}, \mu \mathrm{g} / \mathrm{L})$ & $263 \pm 10$ & $154 \pm 6$ & $73.3 \pm 2.5$ \\
\hline Accuracy $(\mathrm{RE}, \%)$ & 3.79 & 5.77 & 7.54 \\
\hline \multicolumn{4}{|c|}{ Short-term stability $\left(25^{\circ} \mathrm{C}\right.$ for $\left.3 \mathrm{~h}\right)$} \\
\hline Initial concentration (mean $\pm \mathrm{SD}, \mu \mathrm{g} / \mathrm{L})$ & $278 \pm 22$ & $196 \pm 9$ & $96.2 \pm 7.9$ \\
\hline Concentration determined after stability study (mean $\pm \mathrm{SD}, \mu \mathrm{g} / \mathrm{L})$ & $263 \pm 21$ & $188 \pm 8$ & $108 \pm 10$ \\
\hline Accuracy $(\mathrm{RE}, \%)$ & 5.24 & 3.72 & 12.43 \\
\hline \multicolumn{4}{|c|}{ Freeze-thaw stability (After three freeze-thaw cycles) } \\
\hline Initial concentration $($ mean $\pm \mathrm{SD}, \mu \mathrm{g} / \mathrm{L})$ & $273 \pm 2$ & $145 \pm 15$ & $68.2 \pm 6.0$ \\
\hline Concentration determined after stability study (mean $\pm \mathrm{SD}, \mu \mathrm{g} / \mathrm{L})$ & $260 \pm 18$ & $127 \pm 3$ & $61.2 \pm 4.6$ \\
\hline Accuracy $(\mathrm{RE}, \%)$ & 4.76 & 12.75 & 10.27 \\
\hline \multicolumn{4}{|c|}{ Stability in autosampler $\left(25^{\circ} \mathrm{C}\right.$ for $\left.24 \mathrm{~h}\right)$} \\
\hline Initial concentration (mean $\pm \mathrm{SD}, \mu \mathrm{g} / \mathrm{L})$ & $306 \pm 6$ & $164 \pm 30$ & $107 \pm 3$ \\
\hline Concentration determined after stability study $($ mean $\pm S D, \mu g / L)$ & $307 \pm 5$ & $173 \pm 9$ & $117 \pm 3$ \\
\hline Accuracy $(\mathrm{RE}, \%)$ & 0.29 & 5.17 & 9.28 \\
\hline
\end{tabular}

\subsubsection{In Vivo Study}

The applicability of the validated ion-pair HPLC-UV method was confirmed in the analysis of iodine in urinary samples from 93 pregnant women. Figure 2 shows the measured concentrations of iodine in urine in all pregnant women. The recommended range of UIC in pregnant women by WHO is marked with green lines.

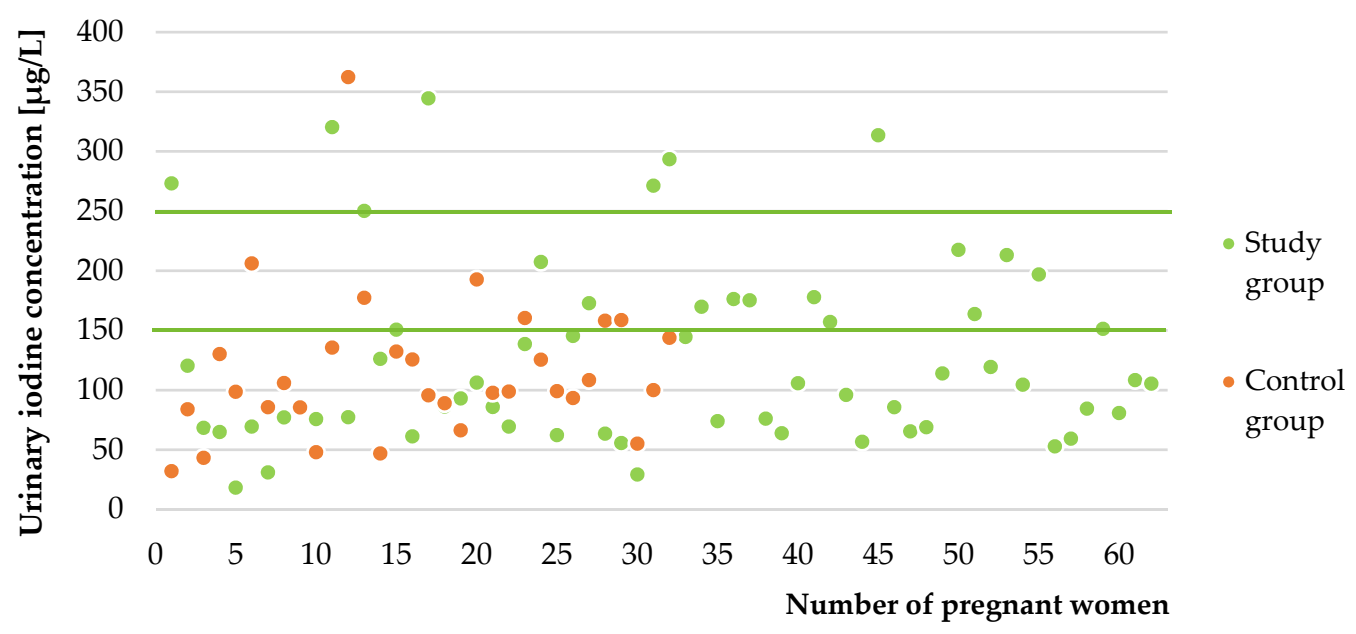

Figure 2. Urinary iodine concentrations in all pregnant women.

The median UIC in all studied women was $127 \mu \mathrm{g} / \mathrm{L}$ (\%CI: 110; 145). The median UIC in patients with iodine supplementation $(133 \mu \mathrm{g} / \mathrm{L}, \% \mathrm{CI}$ : 109; 157) was higher than in 
those who were not taking iodine-containing supplements $(117 \mu \mathrm{g} / \mathrm{L}, \% \mathrm{CI}$ : 95; 138), but the difference was not statistically significant $(p=0.97)$. The distribution of ioduria is shown in Figure 3.

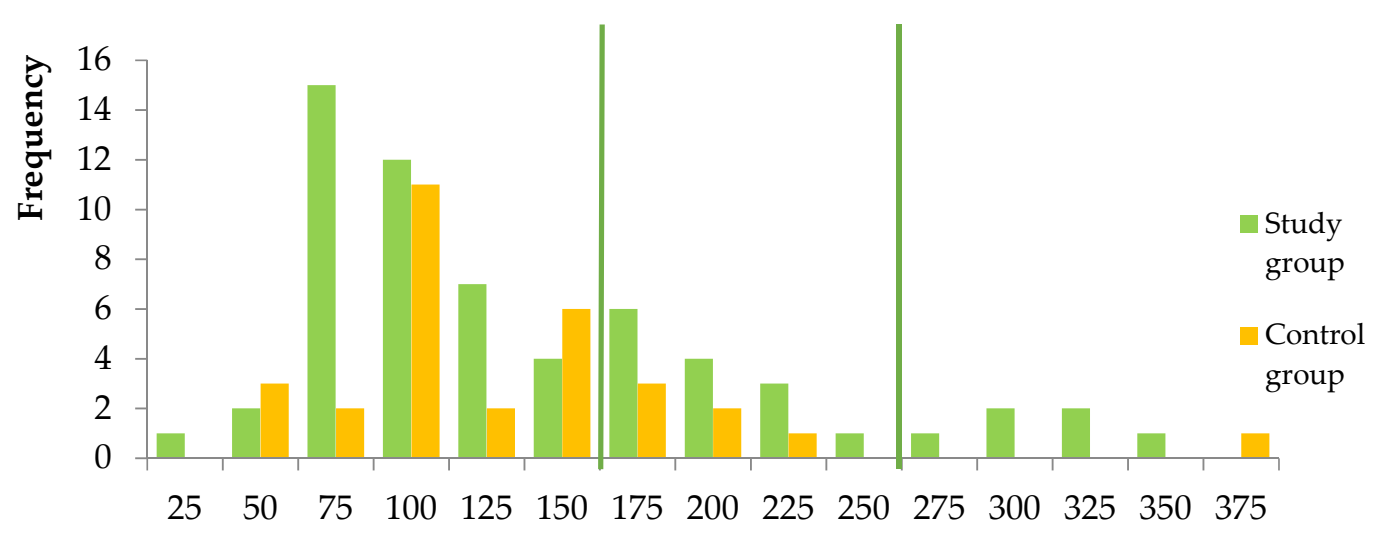

\section{Urinary iodine concentration $[\mu \mathrm{g} / \mathrm{L}]$}

Figure 3. Histogram of the number of women with different levels of urinary iodine concentration.

\section{Discussion}

The measurements of urinary iodine concentration in populations from selected regions help verify the iodine supplementation dose required to reach the recommended iodine supplies in pregnant women. Owing to the pivotal role of iodine for human health and the increasing need for iodine status assessment, an effective, cheap and uncomplicated urinary iodine detection method is required. Different techniques for UIC determination, such as S-K or ICP-MS, have been developed over the years. These methods require expensive instrumentation with qualified personnel (ICP-MS) or an initial digestion step to remove potential interfering substances before analysis by a kinetic colorimetric method [30]. Our study aimed to develop a simple and inexpensive HPLC-UV method to determine the urinary iodine concentration and confirm the applicability of this method in assessing iodine supplies in pregnant women. The sample preparation and the mobile phase composition were based on the method by Cui et al. [37] developed to determine iodine in rabbit plasma. The modifications needed to separate iodide from compounds originating from urine included a different chromatographic column, gradient elution of a mobile phase with slightly different $\mathrm{pH}$ and lower amount of ACN for protein precipitation. Sodium thiosulfate solution was added to urine samples to convert the total free iodine to iodide. The use of octylamine and 18-crown-6 ether in the water phase improved the resolution of iodine from endogenous components present in the urine samples. The $-\mathrm{NH}^{3+}-\mathrm{I}^{-}$ion pair attenuated the negativity of iodide and increased its hydrophobicity, leading to the longer iodide retention on the C 8 column. This effect was enhanced by the addition of 18 -crown- 6 ether, which forms stable complexes with $\mathrm{I}^{-}$[37].

The developed HPLC-UV method was validated. LOD for the analysis of iodine was $18 \mu \mathrm{g} / \mathrm{L}$, which is sensitive enough for clinical utility. The LOQ was $50 \mu \mathrm{g} / \mathrm{L}$ and was sufficient to identify the iodine deficiency. The current LOQ and LOD values were higher than previously reported by the highly specific ICP-MS and S-K methods (Table 4). The precision obtained in our study was $<10 \%$ (Table 2 ). In contrast to the $\mathrm{S}-\mathrm{K}$ method, the developed ion-pair HPLC-UV method does not require digestion or oxidation of the samples before the analysis. In addition, it does not use hazardous chemical. Compared to the ICPMS method, our method is inexpensive and does not require specialized equipment with qualified staff $[30,34]$. Moreover, according to our knowledge, we present the first study on the iodine stability in urine during sample pretreatment and storage. Iodine proved to be stable in urine samples after three freeze-thaw cycles, in a long-term stability study $\left(-20^{\circ} \mathrm{C}\right.$ for 73 days), in a short-term stability test $\left(25^{\circ} \mathrm{C}\right.$ for $\left.3 \mathrm{~h}\right)$ and in the autosampler 
test $\left(24 \mathrm{~h}\right.$ at $\left.25^{\circ} \mathrm{C}\right)$. Our newly developed method fulfils the validation requirements for the analysis of compounds in biological fluids.

Table 4. Characteristics of the methods used for the determination of iodine in urine.

\begin{tabular}{|c|c|c|c|c|c|c|}
\hline Method & Sample Preparation & $\begin{array}{l}\text { Urine } \\
\text { Volume }\end{array}$ & $\begin{array}{l}\text { LOD } \\
{[\mu \mathrm{g} / \mathrm{L}]}\end{array}$ & $\begin{array}{c}\mathrm{LOQ} \\
{[\mu \mathrm{g} / \mathrm{L}]}\end{array}$ & $\begin{array}{l}\text { Precision } \\
\quad[\%]\end{array}$ & Ref. \\
\hline Ion-pair HPLC-UV & $\begin{array}{l}200 \mu \mathrm{L} \text { of sodium thiosulfate solution and } \\
\qquad 50 \mu \mathrm{L} \text { of acetonitrile }\end{array}$ & $200 \mu \mathrm{L}$ & 18 & 50 & $<10$ & - \\
\hline ICP-MS & $\begin{array}{c}\text { dilution (1:20) in an aqueous solution of } \\
0.5 \mathrm{~mL} / \mathrm{L} \text { Triton } \mathrm{X}-100 \text { and suprapure } \\
\text { concentrated } \mathrm{HCl}\end{array}$ & $500 \mu \mathrm{L}$ & 4 & 20 & n.a. & [36] \\
\hline ICP-MS & $\begin{array}{c}\text { dilution (1:9) in } 0.1 \% \text { EDTA and } 0.1 \% \\
\text { ammonia }\end{array}$ & $1 \mathrm{~mL}$ & 3.3 & 10 & 2.2 & [31] \\
\hline ICP-MS & $\begin{array}{l}\text { dilution (1:20) by adding an aqueous solution } \\
\text { containing } 0.1 \mathrm{mg} / \mathrm{L} \text { NH4OH, } 0.1 \mathrm{~g} / \mathrm{L} \text { EDTA, } \\
5 \mathrm{mg} / \mathrm{L} \text {-butanol and } 0.1 \% \text { Triton } \mathrm{X}-100\end{array}$ & $200 \mu \mathrm{L}$ & 0.1 & n.a. & n.a. & [40] \\
\hline ICP-MS & $\begin{array}{l}\text { dilution (1:9) using water with } 1.5 \% \\
\text { isopropanol and } 7 \text { mmol hydrous ammonium }\end{array}$ & $200 \mu \mathrm{L}$ & 0.87 & 8.1 & $<8$ & [34] \\
\hline S-K method & ammonium persulfate as the digestion regent & n.a. & 2.0 & n.a. & $<4$ & [34] \\
\hline S-K method & $\begin{array}{l}\text { dilution with water (1:1), perchloric acid } \\
\text { digestion, incubation } 25 \text { min at } 200{ }^{\circ} \mathrm{C}\end{array}$ & $200 \mu \mathrm{L}$ & n.a. & 13 & $<19.2$ & [31] \\
\hline
\end{tabular}

n.a.-not available; LOD—limit of detection, LOQ—limit of quantitation; ICP-MS—Inductively coupled plasma mass spectrometry; S-K method-Sandell-Kolthoff method.

The method's applicability was evaluated in the assessment of iodine status in pregnant women. The study population was not homogeneous, as it involved healthy women and those with mild thyroid disorders. However, we believe that the population is appropriate to confirm the usefulness of the HPLC-UV method in identifying iodine-deficient subjects. The $\mathrm{WHO}$ guidelines define iodine status for all pregnant women, regardless of concomitant diseases, as adequate when the median UIC is $150-249 \mu \mathrm{g} / \mathrm{L}$ and insufficient when $<150 \mu \mathrm{g} / \mathrm{L}$ [23]. Moreover, in the studied population, the differences in the urine iodine concentration between healthy pregnant women and those with thyroid disorders were statistically insignificant ( $p=0.208$, data not shown).

In our study, the pregnant women without and also with iodine supplementation displayed insufficient iodine intake. More than three-quarters of pregnant women without supplementation were iodine-deficient. Additionally, the study group was deficient in iodine, despite taking daily iodine doses offered as dietary supplements dedicated for pregnant females. The median UIC of all pregnant women $(127 \mu \mathrm{g} / \mathrm{L})$ was lower than sufficient iodine status according to $\mathrm{WHO}$ criteria. Our results are consistent with previous data. In recent years, several studies have assessed UIC in pregnant women. Most of them showed low median UIC, suggesting insufficient iodine status in pregnancy [25,41-48].

Despite the introduction of salt iodization programs, iodine deficiency remains a significant public health problem in Europe $[12,49,50]$. Further research should be performed on a larger group to confirm our results and develop optimal strategies for preventing and treating iodine deficiency.

\section{Limitations and Strength of the Study}

This study has some limitations. The first is the small number of individuals. It is worth considering expanding the study population, and the groups should be more homogeneous, with normal thyroid function and without levothyroxine treatment. Moreover, the study contained only Caucasian pregnant females from one province, although conducted at a tertiary reference center for gynecology, obstetrics and neonatology, currently the biggest gynecological hospital in Greater Poland. Another limitation is that women 
were recruited, and spot urine samples were collected, only during the third trimester of pregnancy. It is worth analyzing the iodine status, including all trimesters of gestation, using $24 \mathrm{~h}$ iodine collection samples or the iodine-to-creatinine ratio instead of spot urinary collection. Moreover, an internal standard (IS) was not used for the method validation.

The key strength of the study included the development and validation of a new ion-pair HPLC-UV method for the determination of iodine in urine. This is the first study to establish iodine status by the ion-pair HPLC-UV method in human urine to the best of our knowledge. The method is less complicated and expensive than other methods frequently used. Moreover, the stability study of iodine in urine samples was performed for the first time.

\section{Materials and Methods}

\subsection{Chemicals and Reagents}

Potassium iodide (99\% purity), octylamine ( $99 \%$ purity), 18 -crown- 6 ether ( $99 \%$ purity), sodium thiosulfate ( $99 \%$ purity), phosphoric acid (BioUltra, $\geq 85 \%$ purity) were obtained from Sigma-Aldrich (Steinheim, Germany). Acetonitrile (HPLC-grade) was purchased from Merck KGaA (Darmstadt, Germany). Ultra-pure water was generated in-house using a Simplicity ${ }^{\circledR}$ Water Purification System from Merck Millipore (Burlington, MA, USA).

\subsection{Ion-Pair HPLC-UV Conditions and Apparatus}

The study was conducted using an HPLC Agilent 1100 Series set (Agilent Technologies Inc., Santa Clara, CA, USA). To process the data, the Agilent ChemStation for LC 3D system (Agilent Technologies Inc., Waldbronn, Germany) was used. The chromatographic separation was performed on a Pursuit XRs C 8 column $(250 \times 4.0 \mathrm{~mm}, 5 \mu \mathrm{m}$; Agilent Technologies Inc., Santa Clara, CA, USA). The column temperature was maintained constantly at $20^{\circ} \mathrm{C}$ using a thermostatically controlled column oven. The mobile phase consisted of a mixture of water phase A ( $10 \mathrm{mmol} / \mathrm{L} 18$-crown- 6 ether, $5 \mathrm{mmol} / \mathrm{L}$ octylamine and $5 \mathrm{mmol} / \mathrm{L}$ sodium dihydrogen phosphate, $\mathrm{pH}$ adjusted to 5.95 with phosphoric acid) and acetonitrile (mobile phase B). Following its preparation, the water phase mixture was filtered under vacuum through a $0.45 \mu \mathrm{m}$ membrane filter and degassed in the ultrasonic bath before use. Chromatographic separation of iodine from endogenous compounds was accomplished at a $1.2 \mathrm{~mL} / \mathrm{min}$ flow rate with $12 \%$ mobile phase B. The injected sample volume was $50 \mu \mathrm{L}$. The UV detection was performed at $225 \mathrm{~nm}$.

\subsection{Preparation of Standard Solutions and Quality Control Samples}

A stock solution of iodine at a concentration of $1 \mathrm{mg} / \mathrm{mL}$ was prepared by dissolving $13.08 \mathrm{mg}$ of $\mathrm{KI}$ in $10 \mathrm{~mL}$ of ultra-pure water. Working standard solutions at 0, 500, 750, 1000, $1500,2000,2500$ and $3000 \mu \mathrm{g} / \mathrm{L}$ of iodine were prepared from stock solution by dilution in ultra-pure water.

Calibration standards were prepared by spiking $180 \mu \mathrm{L}$ of ultra-pure water with $20 \mu \mathrm{L}$ of the working standard solutions to give nominal concentrations of $0,50,75,100,150,200$, 250 and $300 \mu \mathrm{g} / \mathrm{L}$. The calibration curve standards were freshly prepared from the working standard solutions for each validation and assay run. Quality control samples (QCs) were independently prepared directly before analysis at four concentration levels of 50, 75, 150 and $250 \mu \mathrm{g} / \mathrm{L}$.

\subsection{Sample Preparation}

A volume of $200 \mu \mathrm{L}$ of sodium thiosulfate solution ( $5 \mathrm{~g} / \mathrm{L}$ ) was added to $200 \mu \mathrm{L}$ calibration standards or QCs. Tubes were capped and then mixed by vortex for $1 \mathrm{~min}$. After that, $50 \mu \mathrm{L}$ of acetonitrile was added to each sample, followed by vortexing for $2 \mathrm{~min}$. The mixture was centrifuged at $2500 \times g$ for $10 \mathrm{~min}$. After mixing, the sample was conveyed to a new glass vial, and $50 \mu \mathrm{L}$ was injected into the HPLC system. Patients' urine samples $(200 \mu \mathrm{L})$ were also subjected to the above procedure. For each subject sample, the analysis was performed in duplicate. 


\subsection{Method Validation}

The developed method was validated for linearity, precision, accuracy, stability in different conditions, LOD and LOQ following guidelines on bioanalytical method validation of the EMA [39].

Linearity was estimated for the peak area of iodide as a function of the iodine concentration covering the range of $50-300 \mu \mathrm{g} / \mathrm{L}$ in urine. Equations generated from the calibration curve were used for calculating the concentrations of iodine in the patient's urine.

The method inter-day and intra-day precision and accuracy were calculated based on QCs. Five replicates were spiked with LOQ $(50 \mu \mathrm{g} / \mathrm{L})$, low $(75 \mu \mathrm{g} / \mathrm{L})$, medium $(150 \mu \mathrm{g} / \mathrm{L})$ and high $(250 \mu \mathrm{g} / \mathrm{L})$ concentrations. The analysis of the total number of replicates was conducted during one day and over five consecutive days. The precision was calculated as relative standard deviation (RSD; $\left.\mathrm{SD} / \mathrm{C}_{\text {measured }}\right) \cdot 100 \%$. The accuracy was estimated as a relative error $\left(\% R E ;\left(\left(C_{\text {nominal }}-C_{\text {measured }}\right) \times 100 \% / C_{\text {nominal }}\right)\right.$.

LOD was defined as the smallest concentration of iodine that could be detected with the corresponding signal-to-noise $(\mathrm{S} / \mathrm{N})$ ratio greater than 3:1. LOQ was determined as the lowest concentration of iodine determined by the method with the precision and accuracy $\leq 20 \%$.

Iodine stability was evaluated with three concentrations (low, medium and high) of the patient's urine in three replicates for each concentration after three freeze-thaw cycles, long-term (over 2 months at $\left.-20^{\circ} \mathrm{C}\right)$ and short-term $\left(3 \mathrm{~h}\right.$ at $\left.25^{\circ} \mathrm{C}\right)$ storage, and after standing of the prepared samples in autosampler for $24 \mathrm{~h}$ at $25^{\circ} \mathrm{C}$. The samples were prepared according to the procedure described above. Based on the EMA guidelines for bioanalytical method validation, the stability of the analyte is confirmed if the deviation from the nominal concentration is within $\pm 15 \%$ [39]. For the nominal concentration, we considered the iodine concentration measured after the first thaw of the urine sample.

\subsection{In Vivo Application}

Following the validation of the ion-pair HPLC-UV method, it was used to determine the iodine concentration in the urine of 93 Caucasian pregnant women. Patients were recruited at the Department of Obstetrics and Gynecology of Poznan University of Medical Sciences at planned admission to the obstetric ward of the gynecological hospital. They were divided into two groups: 61 women declaring iodine supplementation (study group) to the amount of 150-200 $\mu$ g per day (183 $\pm 26 \mu \mathrm{g} /$ daily) and 32 without iodine supplementation (control group). Both groups consisted of pregnant women of similar age (32.7 \pm 3.8 years) who lived in the same geographical area of Greater Poland. Women who had poor health (including kidney or liver dysfunction, the necessity of chronic medication intake other than levothyroxine) according to physical examination and laboratory analyses following an interview were excluded from the study. Included females were healthy or affected by benign thyroid disorders (thyroid nodules, autoimmune thyroid diseases, hypothyroidism) with or without levothyroxine treatment. A single spot urine sample was obtained from mothers at admission before delivery to measure iodine concentration. The urine samples were stored at $-20{ }^{\circ} \mathrm{C}$ until use and were allowed to thaw at room temperature before processing.

The study was approved by the Local Bioethics Committee of Poznan University of Medical Sciences (approval number 104/19). Participation in the study was voluntary. Each participant gave written informed consent after having been informed about the project's purpose and course. The study has been conducted according to outlined ethical principles in the Declaration of Helsinki [51].

\subsection{Data Processing and Statistical Analysis}

Statistical analysis of the results was conducted using Statistica 13 software with Medical Set (StatSoft, Tulsa, OK, USA). Continuous data were presented as median and confidence interval $(\% \mathrm{CI})$. The normality of the data distribution was assessed using the Shapiro-Wilk test. The results were analyzed statistically, using elements of descriptive 
statistics and statistical procedures, such as correlation analysis (Spearman test for nonnormal distributions). Comparisons between groups were performed using the MannWhitney $U$ test for non-normal data distribution. The level of statistical significance was taken as $p<0.05$.

\section{Conclusions}

This developed simple and low-cost ion-pair HPLC-UV method for determining iodine in human urine is accurate, repeatable, reproducible, and precise and was applied to analyze iodine in the urine of 93 pregnant women. Most pregnant females were iodinedeficient, according to WHO guidelines, independent of iodine supplementation. Further research, with a larger and more homogeneous population of pregnant women, should be performed to evaluate urinary iodine levels in this population. This newly established and validated method is less complicated and expensive than other frequently used assays and may be applicable for monitoring iodine status to prevent iodine deficiency, especially in pregnant women.

Author Contributions: Conceptualization, M.K.-Ł., A.A.M. and D.F.; Methodology, M.K.-Ł., A.A.M. and D.F.; Formal Analysis, M.K.-Ł. and A.A.M.; Investigation, M.K.-Ł., A.A.M., D.F. and E.S.-P.; Resources, D.F., E.S.-P., M.R. and F.K.G.; Data Curation, M.K.-Ł., A.A.M. and D.F.; Writing-Original Draft Preparation, M.K.-Ł., A.A.M. and D.F.; Writing—Review \& Editing, M.K.-Ł., A.A.M., D.F., F.K.G., M.R., E.S.-P. and M.B.; Visualization, M.K.-Ł., A.A.M. and D.F.; Supervision, M.K.-Ł., M.R. and F.K.G.; Project Administration, M.K.-Ł., A.A.M., D.F. and E.S.-P.; Funding Acquisition, D.F. and M.R. All authors have read and agreed to the published version of the manuscript.

Funding: The research was funded by the PRELUDIUM-17 grant from the Polish National Centre for Science (2019/33/N/NZ5/02303). The authors would like to thank Poznan University of Medical Sciences for the financial support of the paper.

Institutional Review Board Statement: The study was conducted according to the guidelines of the Declaration of Helsinki and approved by The Local Bioethics Committee of Poznan University of Medical Sciences (protocol no. 104/19, date of approval: 10 January 2019).

Informed Consent Statement: Informed consent was obtained from all subjects involved in the study.

Data Availability Statement: The data presented in this study are available on request from the corresponding author. The data are not publicly available due to privacy restrictions.

Conflicts of Interest: The authors declare no conflict of interest.

\section{References}

1. Andersson, M.; Karumbunathan, V.; Zimmermann, M.B. Global Iodine Status in 2011 and Trends over the Past Decade. J. Nutr. 2012, 142, 744-750. [CrossRef]

2. Zimmermann, M.B.; Jooste, P.L.; Pandav, C.S. Iodine-Deficiency Disorders. Lancet 2008, 372, 1251-1262. [CrossRef]

3. O'Kane, S.M.; Mulhern, M.S.; Pourshahidi, L.K.; Strain, J.J.; Yeates, A.J. Micronutrients, Iodine Status and Concentrations of Thyroid Hormones: A Systematic Review. Nutr. Rev. 2018, 76, 418-431. [CrossRef] [PubMed]

4. Filipowicz, D.; Majewska, K.; Kalantarova, A.; Szczepanek-Parulska, E.; Ruchała, M. The Rationale for Selenium Supplementation in Patients with Autoimmune Thyroiditis, According to the Current State of Knowledge. Endokrynol. Pol. 2021, 72, 153-162. [CrossRef] [PubMed]

5. Biban, B.; Lichiardopol, C. Iodine Deficiency, Still a Global Problem? Curr. Health Sci. J. 2017, 43, 103-111. [CrossRef]

6. Ha, S.K. Dietary Salt Intake and Hypertension. Electrolyte Blood Press. 2014, 12, 7-18. [CrossRef]

7. Musso, N.; Conte, L.; Carloni, B.; Campana, C.; Chiusano, M.C.; Giusti, M. Low-Salt Intake Suggestions in Hypertensive Patients Do Not Jeopardize Urinary Iodine Excretion. Nutrients 2018, 10, 1548. [CrossRef]

8. Sant'Ana Leone de Souza, L.; de Oliveira Campos, R.; Dos Santos Alves, V.; Cerqueira, T.L.O.; da Silva, T.M.; Teixeira, L.S.G.; Feitosa, A.C.R.; de Aragão Dantas Alves, C.; Ramos, H.E. Hypertension and Salt-Restrictive Diet Promotes Low Urinary Iodine Concentration in High-Risk Pregnant Women: Results from a Cross-Sectional Study Conducted After Salt Iodination Reduction in Brazil. Biol. Trace Elem. Res. 2020, 197, 445-453. [CrossRef]

9. Alexander, E.K.; Pearce, E.N.; Brent, G.A.; Brown, R.S.; Chen, H.; Dosiou, C.; Grobman, W.A.; Laurberg, P.; Lazarus, J.H.; Mandel, S.J.; et al. 2017 Guidelines of the American Thyroid Association for the Diagnosis and Management of Thyroid Disease During Pregnancy and the Postpartum. Thyroid 2017, 27, 315-389. [CrossRef] [PubMed] 
10. Iodine Global Network (IGN)—Global Iodine Nutrition Scorecard and Map. Available online: https://www.ign.org/scorecard. htm (accessed on 19 April 2021).

11. Hubalewska-Dydejczyk, A.; Lewiński, A.; Milewicz, A.; Radowicki, S.; Poręba, R.; Karbownik-Lewińska, M.; Kostecka-Matyja, M.; Trofimiuk-Müldner, M.; Pach, D.; Zygmunt, A.; et al. Management of Thyroid Diseases during Pregnancy. Endokrynol. Pol. 2011, 62, 362-381. [PubMed]

12. Zimmermann, M.B.; Gizak, M.; Abbott, K.; Andersson, M.; Lazarus, J.H. Iodine Deficiency in Pregnant Women in Europe. Lancet Diabetes Endocrinol. 2015, 3, 672-674. [CrossRef]

13. Zimmer, M.; Sieroszewski, P.; Oszukowski, P.; Huras, H.; Fuchs, T.; Pawlosek, A. Polish Society of Gynecologists and Obstetricians Recommendations on Supplementation during Pregnancy. Ginekol. Pol. 2020, 91, 644-653. [CrossRef]

14. Pearce, E.N.; Lazarus, J.H.; Moreno-Reyes, R.; Zimmermann, M.B. Consequences of Iodine Deficiency and Excess in Pregnant Women: An Overview of Current Knowns and Unknowns. Am. J. Clin. Nutr. 2016, 104 (Suppl. 3), 918S-923S. [CrossRef] [PubMed]

15. Toloza, F.J.K.; Motahari, H.; Maraka, S. Consequences of Severe Iodine Deficiency in Pregnancy: Evidence in Humans. Front. Endocrinol. 2020, 11. [CrossRef]

16. Monaghan, A.M.; Mulhern, M.S.; McSorley, E.M.; Strain, J.J.; Dyer, M.; van Wijngaarden, E.; Yeates, A.J. Associations between Maternal Urinary Iodine Assessment, Dietary Iodine Intakes and Neurodevelopmental Outcomes in the Child: A Systematic Review. Thyroid. Res. 2021, 14, 14. [CrossRef]

17. Abel, M.H.; Caspersen, I.H.; Meltzer, H.M.; Haugen, M.; Brandlistuen, R.E.; Aase, H.; Alexander, J.; Torheim, L.E.; Brantsæter, A.-L. Suboptimal Maternal Iodine Intake Is Associated with Impaired Child Neurodevelopment at 3 Years of Age in the Norwegian Mother and Child Cohort Study. J. Nutr. 2017, 147, 1314-1324. [CrossRef] [PubMed]

18. Bath, S.C.; Steer, C.D.; Golding, J.; Emmett, P.; Rayman, M.P. Effect of Inadequate Iodine Status in UK Pregnant Women on Cognitive Outcomes in Their Children: Results from the Avon Longitudinal Study of Parents and Children (ALSPAC). Lancet 2013, 382, 331-337. [CrossRef]

19. Levie, D.; Korevaar, T.I.M.; Bath, S.C.; Murcia, M.; Dineva, M.; Llop, S.; Espada, M.; van Herwaarden, A.E.; de Rijke, Y.B.; Ibarluzea, J.M.; et al. Association of Maternal Iodine Status With Child IQ: A Meta-Analysis of Individual Participant Data. J. Clin. Endocrinol. Metab. 2019, 104, 5957-5967. [CrossRef] [PubMed]

20. Hynes, K.L.; Otahal, P.; Hay, I.; Burgess, J.R. Mild Iodine Deficiency during Pregnancy Is Associated with Reduced Educational Outcomes in the Offspring: 9-Year Follow-up of the Gestational Iodine Cohort. J. Clin. Endocrinol. Metab. 2013, 98, $1954-1962$. [CrossRef]

21. Reaching Optimal Iodine Nutrition in Pregnant and Lactating Women and Young Children. Available online: https://www.who. int/publications/m/item/WHO-statement-IDD-pregnantwomen-children (accessed on 14 April 2021).

22. World Health Organization. Assessment of Iodine Deficiency Disorders and Monitoring Their Elimination: A Guide for Programme Managers; World Health Organization: Geneva, Switzerland, 2007; ISBN 978-92-4-159582-7.

23. WHO. Urinary Iodine Concentrations for Determining Iodine Status in Populations. Available online: http://www.who.int/ vmnis/indicators/urinaryiodine/en/ (accessed on 14 April 2021).

24. Harding, K.B.; Peña-Rosas, J.P.; Webster, A.C.; Yap, C.M.; Payne, B.A.; Ota, E.; De-Regil, L.M. Iodine Supplementation for Women during the Preconception, Pregnancy and Postpartum Period. Cochrane Database Syst. Rev. 2017, 3, CD011761. [CrossRef]

25. Jiang, H.; Powers, H.J.; Rossetto, G.S. A Systematic Review of Iodine Deficiency among Women in the UK. Public Health Nutr. 2019, 22, 1138-1147. [CrossRef] [PubMed]

26. Wainwright, P.; Cook, P. The Assessment of Iodine Status-Populations, Individuals and Limitations. Ann. Clin. Biochem. 2019, 56, 7-14. [CrossRef] [PubMed]

27. Zimmermann, M.B. Methods to Assess Iron and Iodine Status. Br. J. Nutr. 2008, 99 (Suppl. 3), S2-S9. [CrossRef]

28. König, F.; Andersson, M.; Hotz, K.; Aeberli, I.; Zimmermann, M.B. Ten Repeat Collections for Urinary Iodine from Spot Samples or 24-Hour Samples Are Needed to Reliably Estimate Individual Iodine Status in Women. J. Nutr. 2011, 141, 2049-2054. [CrossRef]

29. Perrine, C.G.; Cogswell, M.E.; Swanson, C.A.; Sullivan, K.M.; Chen, T.-C.; Carriquiry, A.L.; Dodd, K.W.; Caldwell, K.L.; Wang, C.-Y. Comparison of Population Iodine Estimates from 24-Hour Urine and Timed-Spot Urine Samples. Thyroid 2014, 24, 748-757. [CrossRef] [PubMed]

30. Shelor, C.P.; Dasgupta, P.K. Review of Analytical Methods for the Quantification of Iodine in Complex Matrices. Anal. Chim. Acta 2011, 702, 16-36. [CrossRef] [PubMed]

31. Haap, M.; Roth, H.J.; Huber, T.; Dittmann, H.; Wahl, R. Urinary Iodine: Comparison of a Simple Method for Its Determination in Microplates with Measurement by Inductively-Coupled Plasma Mass Spectrometry. Sci. Rep. 2017, 7, 39835. [CrossRef]

32. Eastman, C.J.; Ma, G.; Li, M. Optimal Assessment and Quantification of Iodine Nutrition in Pregnancy and Lactation: Laboratory and Clinical Methods, Controversies and Future Directions. Nutrients 2019, 11, 2378. [CrossRef]

33. Khazan, M.; Azizi, F.; Hedayati, M.; Hedayati, M. A Review on Iodine Determination Methods in Salt and Biological Samples. Scimetr 2013, 1. [CrossRef]

34. Yu, S.; Yin, Y.; Cheng, Q.; Han, J.; Cheng, X.; Guo, Y.; Sun, D.; Xie, S.; Qiu, L. Validation of a Simple Inductively Coupled Plasma Mass Spectrometry Method for Detecting Urine and Serum Iodine and Evaluation of Iodine Status of Pregnant Women in Beijing. Scand. J. Clin. Lab. Investig. 2018, 78, 501-507. [CrossRef] 
35. Li, Y.; Ding, S.; Han, C.; Liu, A.; Shan, Z.; Teng, W.; Mao, J. Concentration-Dependent Differences in Urinary Iodine Measurements Between Inductively Coupled Plasma Mass Spectrometry and the Sandell-Kolthoff Method. Biol. Trace Elem. Res. 2020. [CrossRef] [PubMed]

36. Macours, P.; Aubry, J.C.; Hauquier, B.; Boeynaems, J.M.; Goldman, S.; Moreno-Reyes, R. Determination of Urinary Iodine by Inductively Coupled Plasma Mass Spectrometry. J. Trace Elem. Med. Biol. 2008, 22, 162-165. [CrossRef]

37. Cui, L.; Wen, J.; Zhou, T.; Wang, S.; Fan, G. Optimization and Validation of an Ion-Pair RP-HPLC-UV Method for the Determination of Total Free Iodine in Rabbit Plasma: Application to a Pharmacokinetic Study. Biomed. Chromatogr. 2009, 23, 1151-1159. [CrossRef]

38. Ion Pair Chromatography-An Overview I ScienceDirect Topics. Available online: https://www.sciencedirect.com/topics/ chemistry/ion-pair-chromatography (accessed on 15 September 2021).

39. Bioanalytical Method Validation. Available online: https://www.ema.europa.eu/en/bioanalytical-method-validation (accessed on 14 April 2021).

40. Mizéhoun-Adissoda, C.; Desport, J.-C.; Houinato, D.; Bigot, A.; Dalmay, F.; Preux, P.-M.; Bovet, P.; Moesch, C. Evaluation of Iodine Intake and Status Using Inductively Coupled Plasma Mass Spectrometry in Urban and Rural Areas in Benin, West Africa. Nutrition 2016, 5, 560-565. [CrossRef]

41. Wang, Z.; Zhu, W.; Mo, Z.; Wang, Y.; Mao, G.; Wang, X.; Lou, X. An Increase in Consuming Adequately Iodized Salt May Not Be Enough to Rectify Iodine Deficiency in Pregnancy in an Iodine-Sufficient Area of China. Int. J. Environ. Res. Public Health 2017, 14, 206. [CrossRef]

42. Mioto, V.C.B.; Monteiro, A.C.D.C.N.; de Camargo, R.Y.A.; Borel, A.R.; Catarino, R.M.; Kobayashi, S.; Chammas, M.C.; Marui, S. High Prevalence of Iodine Deficiency in Pregnant Women Living in Adequate Iodine Area. Endocr. Connect. 2018, 7, $762-767$. [CrossRef] [PubMed]

43. Snart, C.J.P.; Keeble, C.; Taylor, E.; Cade, J.E.; Stewart, P.M.; Zimmermann, M.; Reid, S.; Threapleton, D.E.; Poston, L.; Myers, J.E.; et al. Maternal Iodine Status and Associations with Birth Outcomes in Three Major Cities in the United Kingdom. Nutrients 2019, 11, 441. [CrossRef] [PubMed]

44. Knight, B.A.; Shields, B.M.; He, X.; Pearce, E.N.; Braverman, L.E.; Sturley, R.; Vaidya, B. Iodine Deficiency amongst Pregnant Women in South-West England. Clin. Endocrinol. 2017, 86, 451-455. [CrossRef]

45. Dahl, L.; Wik Markhus, M.; Sanchez, P.V.R.; Moe, V.; Smith, L.; Meltzer, H.M.; Kjellevold, M. Iodine Deficiency in a Study Population of Norwegian Pregnant Women—Results from the Little in Norway Study (LiN). Nutrients 2018, 10, 513. [CrossRef]

46. Manousou, S.; Andersson, M.; Eggertsen, R.; Hunziker, S.; Hulthén, L.; Nyström, H.F. Iodine Deficiency in Pregnant Women in Sweden: A National Cross-Sectional Study. Eur. J. Nutr. 2020, 59, 2535-2545. [CrossRef]

47. Torres, M.-T.; Vila, L.; Manresa, J.-M.; Casamitjana, R.; Prieto, G.; Toran, P.; Falguera, G.; Francés, L. The IODEGEST Study Group Impact of Dietary Habit, Iodine Supplementation and Smoking Habit on Urinary Iodine Concentration During Pregnancy in a Catalonia Population. Nutrients 2020, 12, 2656. [CrossRef] [PubMed]

48. Manousou, S.; Eggertsen, R.; Hulthén, L.; Filipsson Nyström, H. A Randomized, Double-Blind Study of Iodine Supplementation during Pregnancy in Sweden: Pilot Evaluation of Maternal Iodine Status and Thyroid Function. Eur. J. Nutr. 2021. [CrossRef] [PubMed]

49. Ittermann, T.; Albrecht, D.; Arohonka, P.; Bilek, R.; de Castro, J.J.; Dahl, L.; Filipsson Nystrom, H.; Gaberscek, S.; Garcia-Fuentes, E.; Gheorghiu, M.L.; et al. Standardized Map of Iodine Status in Europe. Thyroid 2020, 30, 1346-1354. [CrossRef] [PubMed]

50. Iodine Deficiency in Europe: A Continuing Public Health Problem. Available online: https://www.who.int/publications/i/ item/9789241593960 (accessed on 22 June 2021).

51. World Medical Association Declaration of Helsinki. Ethical Principles for Medical Research Involving Human Subjects I Global Health I JAMA I JAMA Network. Available online: https: / /jamanetwork.com/journals/jama/fullarticle/1760318 (accessed on 14 April 2021). 